\title{
Level of Interleukin-35, Interleukin-36, and the Interleukin-35/ Interleukin-36 Ratio in Juvenile Idiopathic Arthritis
}

\author{
Qudus W. Jamal ${ }^{1}$, Ghassaq Alubaidi2*(iD), Yasmin A. Humadi ${ }^{3}$ \\ ${ }^{1}$ Department of Microbiology, College of Medicine, Nahrain University, Baghdad, Iraq; ${ }^{2}$ Medical Research Unit, College of \\ Medicine, Nahrain University, Baghdad, Iraq; ${ }^{3}$ Department of Internal Medicine, College of Medicine, Nahrain University, \\ Baghdad, Iraq
}

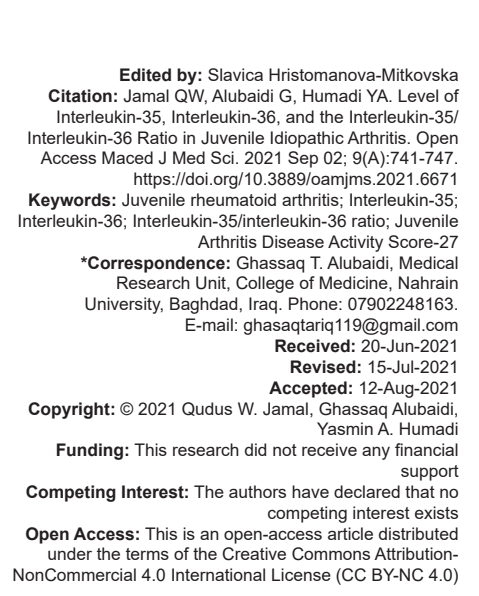

Abstract

BACKGROUND: Cytokines are inflammatory mediators that regulate multiple processes potentially implicated in inflammation and autoimmunity.

AIM: This study aimed to investigate the levels of circulating interleukin (IL)-35, IL-36, and IL-35/IL-36 ratio in Juvenile Idiopathic Arthritis (JIA) patients.

METHODS: Fifty-one patients categorized based on the International League of Associations for Rheumatology classification criteria were enrolled, along with 46 healthy controls. Disease activity assessment was conducted according to the Juvenile Arthritis Disease Activity Score (JADAS-27) system. Serum cytokine levels were determined using the sandwich enzyme-linked immunosorbent assay.

RESULTS: Compared to controls, the serum levels of IL-36 were significantly higher among JIA children $(p=0.002)$ and serum IL-35 levels and the IL-35/IL-36 ratio were significantly lower in the patients $(p=0.002, p<0.001$, respectively). Furthermore, the IL-35/IL-36 serum ratio, but not the absolute IL levels, correlated positively with the JADAS-27, giving a good indication of the disease outcome. Further, the IL-35/IL-36 serum ratio showed higher sensitivity and specificity compared to the absolute cytokine levels.

CONCLUSION: A significant change in the circulating IL-35 and IL-36 levels and an imbalance in the IL35/IL36 ratio occur in JIA. This study is a novel attempt to explore the role of IL-35 and IL-36 in JIA; further studies are required to support our results. The IL-35/II-36 ratio is a promising immunological marker to predict, diagnose, and monitor JIA.

\section{Introduction}

Juvenile idiopathic arthritis (JIA) is the most common pediatric rheumatic disorder with a multifactorial autoimmune etiology. The etiopathogenesis of JIA involves a combination of both genetic factors and early exposure to harmful environmental stimuli [1]. Physiologically, the immune system comprises dynamic components that guarantee an appropriate, rapid, and precise response to foreign pathogens. Whereas, dysregulated immune mediators result in the autoinflammatory process, that is, an imbalance of the immune mediators leads to loss of homeostasis and consequently triggers an autoimmune pathology [2]. It is believed that an exaggerated production of certain cytokines is involved in the development of synovial inflammation as well as the systemic manifestations in JIA. Of these cytokines, tumor necrosis factor $\alpha$ (TNF- $\alpha$ ), interleukin $1 \beta$ (IL-1 $\beta)$, and IL- 6 are most notably involved [3], [4].

TNF- $\alpha$ is a key contributor to the pathogenesis of JIA - the soluble TNF- $\alpha /$ TNF-receptor- 1 axis is mostly correlated to proapoptotic and inflammatory diseases, while the membrane-bound TNF- $\alpha / T N F-$ receptor-2 axis is associated with immune regulation. Therefore, biologics that selectively target TNF receptors (TNFRs) are superior to drugs that randomly block TNF- $\alpha$ and permit differential activation/inhibition of TNFRs [5]. Moreover, raised levels of circulating TNF and predominant TNF- R2 expression in immune cells were recorded in JIA patients [4], [5]. Likewise, IL-1, a pro-inflammatory cytokine, strongly induces IL-6 synthesis by fibroblasts during both acute and chronic inflammation. Whereas, IL-1 and IL-17 act synergistically to cause cartilage destruction in JIA. Furthermore, it is reported that IL-1 and TNF- $\alpha$ together enhance the IL-23-mediated production of IL-17, and both IL -1 and IL-23 act in harmony to enhance the $\mathrm{T}$ helper- (Th-)17 response [4], [6]. Further, recent studies have reported the role of IL-17 in initiating both joint inflammation and cartilage destruction in JIA [7]. Many studies have identified the role of IL-6 in systemic JIA (SJIA); IL-6 is primarily involved in osteoclastic activation and proliferation [4]. Significantly elevated levels in the blood and synovia of patients just before the fever spikes contribute to the disease's clinical course. Therefore, the recent 
advanced strategies to manage JIA include IL-1 and IL-6-directed therapies [6].

Over the past two decades, the research on cytokines has intensified, and new members have been added to the list of cytokines; however, the literature is scarce on cytokines IL-30 through IL-40 [8]. First described in 1997, IL-35 is an anti-inflammatory cytokine belonging to the IL-12 family and has an immunosuppressive effect mediated through regulatory T- and B-lymphocytes. IL-35 was reportedly similar to $\mathrm{IL}-10$ and transfactor growth factor- $\beta$ (TGF- $\beta$ ) in promoting the suppressive activity of T-regulator (T-reg) cells through direct implementation on the cytotoxic T-lymphocyte antigen-4 and B7 pathways [2], [8]. While IL-35 prohibits T-cell proliferation, it does not participate in the conversion of Th-1 cells to T-reg; also, it blocks the Th-2 differentiation by repressing the expression of IL-4 and GATA-3 [8]. Although little is known about the role of IL-35 in autoimmune disorders, in vivo studies on autoimmunity models suggest a potential regulatory effect of IL-35 through the IL-10 dependent pathway [9]. Furthermore, IL-35 demonstrated a protective role in mice with experimental autoimmune (EA) encephalomyelitis, EA uveitis, allergy, diabetes, and colitis [8]. Another in vivo study on mice with collagen-induced arthritis reported that IL-35 significantly promotes T-reg propagation, along with a remarkable increase in IL-10 level and decline in Th-17 differentiation [10].

The IL-36 was first discovered in 1999 and belongs to the IL-1 family, exerting a pro-inflammatory influence. In vitro studies revealed that IL-36-agonists promote human keratinocytes to produce proinflammatory cytokines and chemokines [8], [11]. Existing literature emphasizes the contribution of IL-36 in the pathogenesis of human rheumatoid arthritis, pulmonary disorders, and psoriatic arthritis [12]; also, IL-36 gene expression in psoriatic skin lesions was found to correlate positively with Th-17 cell differentiation [11]. This indicates a potential therapeutic role of IL-36 on joint inflammation in both psoriatic and rheumatoid arthritis [13]. IL36 is mainly produced by the synovial CD-138 plasma cells and is upregulated in the synovial tissues of patients with psoriatic or rheumatoid arthritis [14]; elevated levels were also recorded in inflammatory bowel disease (IBD) and mice with experimental sterile inflammation [8].

Therefore, there is a growing need to thoroughly investigate the role of the novel cytokines, IL-35 and IL-36, in the pathogenesis of JIA to substitute the conventional markers in predicting and monitoring the disease occurrence and progress. The present study aimed to explore a possible relationship between IL-35, IL-36, and JIA pathogenicity and disease activity score. A clinical inflammatory index, juvenile arthritis disease activity score (JADAS)-27, was determined along with serum IL-35 and IL-36 levels and the IL-35/ IL-36 ratio in children with JIA; also, their distribution in patients was compared to healthy subjects.

\section{Methods}

\section{Participants}

In this pediatric case-control study, 51 JIA patients and 46 healthy control were included. All children were characterized for JIA according to the International League of Association for Rheumatology criteria as people $<16$ years of age having arthritis in one or more joints that persisted for $>6$ weeks. Patients attending the outpatient Rheumatology Unit at the Imamen Kadhmen Teaching Hospital/Baghdad/Iraq, from April 2019 to September 2019 and presenting with active joint disease (featured by joint swelling, stiffness, warmth, and movement limitation with either pain during movement or tenderness) and systemic disease (fever, fatigue, rash, chest-abdominal pain, and lymphadenopathy) were included in the study.

The control group included age but not sexmatched apparently healthy children. Their blood samples obtained during a visit to the regional public health centers were non-remarkable for rheumatoid factor (RF), C-reactive protein (CRP), and erythrocyte sedimentation ratio (ESR).

Ethical approval for the study was obtained from the Institutional Review Board, College of Medicine, Al-Nahrain University, Baghda, Iraq, (approval no-202107192; dated - August 2, 2021) assigned by Dean of the college/Dr. Nile A. Written informed consents for participation were obtained from the children's parents.

\section{Disease activity assessment}

Only children with active disease (as per the JADAS-27 system) were included in the study. This score contains four composite measures - a global assessment of disease activity using a $10 \mathrm{~cm}$ long visual analog scale (VAS), global parental assessment of the child's condition using another $10 \mathrm{~cm}$ - long VAS, the number of joints with pain/swelling, and the ESR. VAS used in the two parameters was a $10 \mathrm{~cm}$ line, where zero represented "well" state/no activity in the parameter being measured, and 10 indicated extremely unwell [15].

Twenty-seven joints bilaterally were evaluated for active disease in the JADAS-27 - cervical spine, elbows, wrists, $1^{\text {st }}-3^{\text {rd }}$ metacarpophalangeal joints, proximal interphalangeal joints, hips, knees, and ankles. Each active joint scores one point, hence, a maximum score of 27 . The ESR was used with a corrective formula (ESR-20)/10. The JADAS-27 -ESR was calculated by simply adding all four parameters with a resultant score of 0-57 [16].

The cutoff values for disease activity vary according to the category of the disease - for oligoarthritis: Inactive disease $(\leq 1)$, mild disease 
activity (1.1-2), moderate activity disease (2.1-4.2), and severe disease activity (>4.2); for polyarthritis and systemic disease - inactive disease $(\leq 1)$, mild disease activity (1.1-3.8), moderate activity disease (3.9-8.5), and medium disease activity (>8.5) [15], [17]. Children with oligo and polyarthritis were grouped, whereas those with the systemic disease were put in a separate category. The clinical investigation further included disease duration and treatment type (biological and chemical); ESR, CRP, and RF values were obtained as additional tests.

\section{Evaluation of serum IL-35 and IL-36}

Three milliliters of venous blood were obtained from all participants and centrifuged at $7000 \mathrm{rpm}$ for $10 \mathrm{~min}$. Serum at the superficial layer was collected in a new tube and used to detect blood levels of IL-35 and IL-36. A quantitative sandwich enzyme-linked immune sorbent assay (ELISA) was applied to detect both IL-35 (Human IL-35 MyBioSource, USA; sensitivity $<15.6 \mathrm{pg} / \mathrm{ml}$ ) and IL-36 (Human IL-36 MyBioSource, USA; sensitivity $=1.0 \mathrm{ng} / \mathrm{ml}$ ) following the manufacturer instructions. Absorbance was read by the ELISA reader (HumaReader-HS, South Africa) and the results were interpreted based on the standard curve specific for each kit.

\section{Statistical analysis}

All analyses were done using Statistical Package for the Social Science software (version 23). The distribution pattern of the data (normal or nonnormal) was assessed primarily, followed by descriptive analysis (mean \pm standard deviation, SD) of the baseline characteristics and hematological markers since they were normally distributed. The IL values were nonnormal, so their median values were computed.

The two groups were compared using the Mann-Whitney U-test. A receiver operand characteristic (ROC) curve analysis was applied to identify the cutoff values, the area under the curve (AUC), sensitivity (true negative), and specificity (true positive) of the parameters to evaluate their medical diagnostic potential. A p-value of $\leq 0.05$ was chosen for statistical significance.

\section{Results}

\section{Baseline characteristics of participants}

The study included 51 children with JIA (mean age $=10.31 \pm 4.23$ years; male: female $(M: F)$ ratio $=$ $1: 2.1$ ) and 46 healthy controls (mean age $=12.87 \pm$ 3.44 years, $M: F$ ratio $=1: 1$ ). Out of the 51 patients, two were recently diagnosed and did not receive any drug; of the other 49, 29 were receiving biological treatment (anti-TNF- $\alpha$ ) and the other 20 were receiving chemical treatment (humera, methotrexate, azathioprine, and preslone) alone or in combination. Thirty-nine patients had systemic disease; two of them had uveitis; whereas the other 12 had a non-systemic subtype - seven with oligo-arthritis and five with poly-arthritis (Table 1).

Based on the JADAS-27 system, the JIA patients were classified into three groups - mild $(n=26)$, moderate $(n=10)$, and severe $(n=15)$.

The white blood cell (WBC) count and hemoglobin $(\mathrm{Hb})$ for the patients were within the normal ranges of $10 \pm 9 \times 10^{9} \mathrm{cell} / \mathrm{l}$ and $11.1 \pm 1.5 \mathrm{~g} / \mathrm{dl}$, respectively. However, the ESR values were as high as $41 \pm 31 \mathrm{~mm} / \mathrm{hr}$. Regarding the CRP and RF, 31 patients were positive for CRP, and 13 tested positive for the presence of the RF.

In the control group, the WBC, $\mathrm{Hb}$, and ESR values were $11.83 \pm 1.83 \times 10^{9} \mathrm{cell} / \mathrm{l}, 13.91 \pm 2.48 \mathrm{~g} /$ $\mathrm{dl}$, and $11.26 \pm 2.75 \mathrm{~mm} / \mathrm{h}$, respectively. All children in the control group tested negative for CRP and RF. All baseline characteristics are listed in Table 1.

\section{Hematological markers in JIA patients according to their disease activity score}

All JIA patients with a mild, moderate, or severe disease were comparable in terms of mean age $(10.6 \pm 3.66$ years, $9.9 \pm 4.53$ years, and $10 \pm$ 5.15 years, respectively, $p=0.87$ ). Furthermore, the three subgroups were similar in terms of the duration of received treatment $(2.6 \pm 1.84$ years, $2.6 \pm 3.24$ years, and $1.7 \pm 2.98$ years, respectively; $p=0.501)$.

Further, the WBC and $\mathrm{Hb}$ values were also comparable and within the normal range for the three subgroups ( $p=0.928 ; p=0.922$, respectively). However, the ESR was raised in all three groups $(42.8 \pm 31.63 \mathrm{~mm} / \mathrm{h}, 24.0 \pm 19.11 \mathrm{~mm} / \mathrm{h}$, and $49.33 \pm$ $33.69 \mathrm{~mm} / \mathrm{h}$, respectively) with no statistically significant difference $(p=0.124)$ (Table 2$)$.

\section{Comparison of IL-35, IL-36, and the IL-35/} IL36 ratio between JIA patients and controls

On comparing the median IL-35 and IL-36 levels, and the IL-35/IL-36 ratio for the patients and controls, it was observed that the IL-35 level in patients was significantly lower than the healthy controls (23.6 pg/ml vs. $96.8 \mathrm{pg} / \mathrm{ml}$, respectively; $\mathrm{p}<0.05$ ). The IL-36 level in patients was significantly higher than the healthy controls $(2.0 \mathrm{pg} / \mathrm{ml}$ vs. $1.3 \mathrm{pg} / \mathrm{ml}$, respectively; $p$ $<0.05)$. In contrast, the IL-35/IL36 ratio was significantly lower among JIA patients compared to healthy controls (13.77 ng/ml vs. $110.67 \mathrm{ng} / \mathrm{ml}$, respectively; $p<0.001)$ (Table 3). 
Table 1: Baseline characteristics of JIA patients and controls

\begin{tabular}{|c|c|c|c|}
\hline Parameter & Patients $(\mathrm{n}=51)$ & Controls $(n=46)$ & Reference range in children [18] \\
\hline Age (in years) (mean $\pm S D)$, (range) & $10.31 \pm 4.23,(1-15)$ & $12.87 \pm 3.44,(5-15)$ & \\
\hline Sex $(n)$ : Males & 16 & 12 & \\
\hline Females & 35 & 11 & \\
\hline \multicolumn{4}{|l|}{ Therapy $(n)^{\star 1}$} \\
\hline Biological $^{\star^{2}}$ & 29 & - & \\
\hline Chemical ${ }^{{ }^{3}}$ & 20 & - & \\
\hline \multicolumn{4}{|l|}{ Disease subtype: } \\
\hline Systemic & $39^{*^{4}}$ & - & \\
\hline Non-systemic (oligo or polyarthritis) & $12(\mathrm{O}-7, \mathrm{P}-5)$ & - & \\
\hline \multicolumn{4}{|l|}{ Disease activity score: } \\
\hline Mild & 26 & - & \\
\hline Moderate & 10 & - & \\
\hline Severe & 15 & - & \\
\hline WBC (in $\left.10^{\circ} \mathrm{cell} / / \mathrm{l}\right)$ (mean $\pm \mathrm{SD}$ ) (range) & $10.09 \pm 3.95,(2-18.7)$ & $11.83 \pm 1.83,(9-15)$ & $4.5-14.5$ \\
\hline $\mathrm{Hb}(\mathrm{g} / \mathrm{dl})($ mean $\pm \mathrm{SD})($ range $)$ & $11.1 \pm 1.54,(7.4-14.2)$ & $13.91 \pm 2.48,(9-17)$ & $10-15$ \\
\hline $\operatorname{ESR}(\mathrm{mm} / \mathrm{h})($ mean $\pm \mathrm{SD})$, (range) & $41.04 \pm 31.05,(7-123)$ & $11.26 \pm 2.75,(9-15)$ & $<10$ \\
\hline $\mathrm{CRP}(\mathrm{n})$ & & & $10 \mathrm{mg} / \mathrm{l}$ \\
\hline Positive & 31 & 0 & \\
\hline Negative & 20 & 46 & \\
\hline $\mathrm{RF}(\mathrm{n})$ & & & Titer $<1 / 80$ \\
\hline Positive & 13 & 0 & \\
\hline Negative & 38 & 46 & \\
\hline
\end{tabular}

Comparison of IL-35, IL-36, and IL-35/IL36 ratio among JIA patients - systemic versus nonsystemic (oligo/poly)

On comparing the median IL-35 values within the patients, no statistically significant difference was observed (SJIA $=29.55 \mathrm{pg} / \mathrm{ml}$, non-SJIA $=18.7 \mathrm{pg} / \mathrm{ml}$; $p=0.342$ ). Regarding IL-36, similar results were obtained indicating no statistically significant difference between SJIA and non-SJIA patients (SJIA $=1.94 \mathrm{ng} / \mathrm{ml}$, non$\mathrm{SJIA}=2.07 \mathrm{ng} / \mathrm{ml} ; \mathrm{p}=0.619$ ). Finally, a comparison of median IL-35/L36 ratio, no statistically significant differences were observed between the two subtypes of $\mathrm{JIA}(\mathrm{SJIA}=16.1$, non-SJIA $=11.35 ; p=0.300)$ (Table 4).

Table 2: Hematological markers in JIA patients with different disease activity scores determined by JADAS-27

\begin{tabular}{|c|c|c|c|c|}
\hline Parameter & $\begin{array}{l}\text { Mild } \\
n=26 \\
\text { Mean } \pm S D\end{array}$ & $\begin{array}{l}\text { Moderate } \\
\mathrm{n}=10 \\
\text { Mean } \pm \mathrm{SD}\end{array}$ & $\begin{array}{l}\text { Severe } \\
\mathrm{n}=15 \\
\text { Mean } \pm \mathrm{SD}\end{array}$ & $p$-value \\
\hline Age (years) & $10.62 \pm 3.66$ & $9.9 \pm 4.53$ & $10.07 \pm 5.15$ & 0.874 \\
\hline $\begin{array}{l}\text { Period of treatment (biological and } \\
\text { chemical) (years) }\end{array}$ & $2.69 \pm 1.84$ & $2.68 \pm 3.24$ & $1.77 \pm 2.98$ & 0.501 \\
\hline WBC $\left(\times 10^{9} / \mathrm{ml}\right)$ & 9.96 & 9.9 & $10.43 \pm 3.36$ & 0.928 \\
\hline $\mathrm{Hb}(\mathrm{g} / \mathrm{dl})$ & $11.09 \pm 1.68$ & $11.27 \pm 0.53$ & $11.01 \pm 1.8$ & 0.922 \\
\hline $\operatorname{ESR}(\mathrm{mm} / \mathrm{h})$ & $42.81 \pm 31.63$ & $24.0 \pm 19.11$ & $49.33 \pm 33.69$ & 0.124 \\
\hline
\end{tabular}

Comparison of IL-35, IL-36, and IL-35/IL36 ratio among JIA patients according to disease score

When comparing JIA patients based on their disease activity score, it was observed that the median IL-35 was the lowest among patients with severe disease $(19.83 \mathrm{pg} / \mathrm{ml})$, followed by mild disease $(22.53 \mathrm{pg} / \mathrm{ml})$, and moderate disease $(97.81 \mathrm{pg} / \mathrm{ml})$. Regarding the median IL-36, the highest value was recorded in patients with severe disease $(2.66 \mathrm{ng} / \mathrm{ml})$, followed by mild $(1.89 \mathrm{ng} / \mathrm{ml})$ and moderate disease $(1.77 \mathrm{ng} / \mathrm{ml})$. On comparing the IL-35/IL-36 ratio, we found that this ratio was lowest among patients with severe disease (6.4), followed by those with mild disease (14.57) and moderate disease (52.67).
Only the IL- $35 / I-36$ ratio $(p<0.05)$, and not the absolute levels of IL-35 and IL-36 ( $p>0.05$ for both) recorded a significant parallel increase with an increase in disease activity score (Table 5 ).

\section{Analysis of ROC curve among JIA patients versus controls}

The ROC analysis indicated that both IL-35 and IL-36 occupied a non-significant AUC of 0.721 and 0.728 , respectively. The sensitivity (true positive) and specificity (false positive) for IL-35 were $69.6 \%$ and $70.6 \%$, respectively, under a cutoff value of $42.18 \mathrm{pg} /$ $\mathrm{ml}$. For IL-36, the sensitivity and specificity values were $64.7 \%$ and $65.2 \%$, respectively, under a cutoff value of $1.58 \mathrm{ng} / \mathrm{ml}$. In comparison, the IL-35/L-36 ratio recorded a significant AUC (0.806), with $69.6 \%$ sensitivity and $72.5 \%$ specificity, under a cutoff value of 47.13 (Figure 1).

\section{Discussion}

A disturbance in the physiological balance of pro-and anti-inflammatory cytokines is the focus of attention in recent immunology researchers to develop new autoimmune therapies. We aimed to investigate the role of two novel cytokines, IL-35 and IL-36, and their ratio in patients with JIA compared to healthy children.

Our results showed that IL-35 was significantly lower among JIA patients compared with healthy subjects, while no significant differences in the IL-35 level were observed with disease subtype (systemic or non-systemic). IL-35 is an anti-inflammatory cytokine, and accordingly, IL-35 levels were the lowest among those with severe JIA, followed by mild and moderate disease, with no significant difference between the three 
Table 3: Comparison of IL-35, II-36, and IL-35/IL-36 ratio between JIA patients and healthy control

\begin{tabular}{|c|c|c|c|c|c|}
\hline \multirow[t]{2}{*}{ Interleukin } & \multicolumn{2}{|l|}{$\begin{array}{l}\text { Patients } \\
\mathrm{n}=51\end{array}$} & \multicolumn{2}{|l|}{$\begin{array}{l}\text { Controls } \\
n=23\end{array}$} & \multirow[t]{2}{*}{$\mathrm{p}$-value } \\
\hline & Mean \pm SD & Median (range) & Mean \pm SD & Median (range) & \\
\hline IL-35 (pg/ml) & $92.12 \pm 224.17$ & $23.61(1.79-1551.3)$ & $122.77 \pm 100.67$ & $96.88(2.01-360.5)$ & 0.002 \\
\hline IL-36 (ng/ml) & $2.11 \pm 1.24$ & $2.0(0.34-7.14)$ & $1.2 \pm 0.79$ & $1.3(0.07-2.55)$ & 0.002 \\
\hline IL-35/L-36 ratio & $60.41 \pm 117.78$ & $13.77(0.75-678.76)$ & $246.7 \pm 578.22$ & $110.67(12.55-2850.29)$ & $<0.001$ \\
\hline
\end{tabular}

Table 4: Comparison of interleukin-35, interleukin-36, and their ratio according to disease subtype

\begin{tabular}{|c|c|c|c|c|c|}
\hline \multirow[t]{2}{*}{ Interleukin } & \multicolumn{2}{|c|}{$\begin{array}{l}\text { Group-1 (Systemic disease) } \\
\mathrm{n}=39\end{array}$} & \multicolumn{2}{|c|}{$\begin{array}{l}\text { Group-2 (non-systemic disease) } \\
\mathrm{n}=12\end{array}$} & \multirow[t]{2}{*}{$\mathrm{p}$-value } \\
\hline & Mean \pm SD & Median (range) & Mean \pm SD & Median (range) & \\
\hline IL-35 (pg/ml) & $70.69 \pm 89.38$ & $29.55(4.54-372.55)$ & $154.75 \pm 423.15$ & $18.7(1.79-1551.3)$ & 0.342 \\
\hline IL-36 (ng/ml) & $2.06 \pm 1.29$ & $1.94(0.34-7.14)$ & $2.26 \pm 1.11$ & $2.07(0.6-4.18)$ & 0.619 \\
\hline IL-35/IL-36 ratio & $56.98 \pm 87.44$ & $16.1(1.62-394.71)$ & $70.44 \pm 184.61$ & $11.35(0.75-678.76)$ & 0.300 \\
\hline
\end{tabular}

Table 5: Comparison of interleukin-35, interleukin-36, and their ratio according to JADAS-27

\begin{tabular}{|c|c|c|c|c|c|c|c|}
\hline \multirow[t]{2}{*}{ Interleukin } & \multicolumn{2}{|l|}{$\begin{array}{l}\text { Mild } \\
\mathrm{n}=26\end{array}$} & \multicolumn{2}{|l|}{$\begin{array}{l}\text { Moderate } \\
n=10\end{array}$} & \multicolumn{2}{|l|}{$\begin{array}{l}\text { Severe } \\
n=15\end{array}$} & \multirow[t]{2}{*}{$p$-value } \\
\hline & Mean \pm SD & Median (range) & Mean \pm SD & Median (range) & Mean \pm SD & Median (range) & \\
\hline IL-35 (pg/ml) & $119.27 \pm 302.8$ & $22.53(1.79-1551.3)$ & $119.6 \pm 116.98$ & $97.81(8.48-372.55)$ & $26.75 \pm 21.48$ & $19.83(4.54-83.7)$ & 0.129 \\
\hline IL-36 (ng/ml) & $1.89 \pm 1.05$ & $1.89(0.34-4.18)$ & $1.75 \pm 0.85$ & $1.77(0.62-3.67)$ & $2.72 \pm 1.57$ & $2.66(0.6-7.14)$ & 0.083 \\
\hline IL-35/IL-36 ratio & $80.59 \pm 154.8$ & $14.57(0.75-678.7)$ & $75.57 \pm 72.61$ & $52.67(5.13-208.5)$ & $15.31 \pm 16.33$ & $6.4(1.62-50.6)$ & 0.034 \\
\hline
\end{tabular}

disease activity groups. On the contrary, IL-36 levels were significantly higher in JIA children compared to healthy subjects ( $p<0.05$ ), and IL-36 did not show a significant contribution to the systemic or non-systemic disease, with a similar distribution as IL-35 based on disease activity score (severe $>$ mild $>$ moderate).

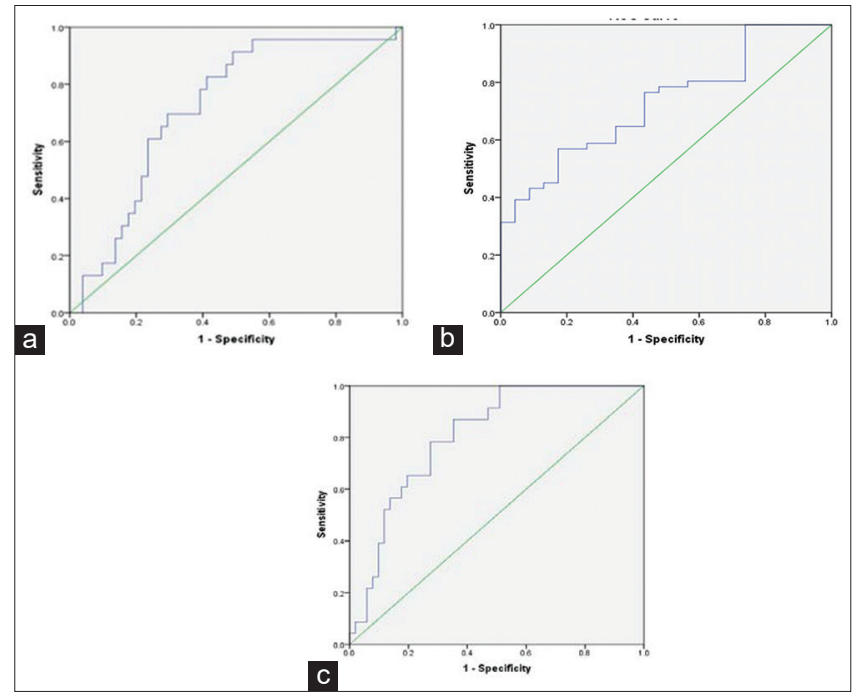

Figure 1: ROC curves of investigated markers (a) IL-35, (b) IL-36, (c) IL-35/IL36 ratio between JIA patients and health control

The IL-35/II-36 ratio was reported as significantly lower in JIA patients compared to healthy controls $(p<0.001)$; no significant differences were detected between SJIA and non-SJIA patients. On the other hand, the IL- 35/IL-36 ratio significantly differed between the three disease activity subgroups $(p<0.05)$ - lowest in patients with severe JIA, followed by mild and moderate JIA disease.

As demonstrated in this study, the significantly reduced IL-35 levels in JIA patients versus controls have also been recorded in other autoimmune diseases. It is believed that IL-35 dysregulation plays a considerable role in the evolution and progress of autoimmune and other inflammatory diseases. In contrast, an elevation in the serum IL-35 levels of patients with autoimmune diseases indicates improvement and upkeep of pro/antiinflammatory cytokines balance. The major biological function of IL-35 is to inhibit both T-cell proliferation and Th-17 differentiation [2], [19].

A lower concentration of plasma IL-35 was detected in psoriatic patients compared to higher levels in healthy controls, suggesting that immunotherapy with IL-35 could ameliorate the pathological features of severe psoriasis [20]. Furthrtmore, IL-35 deficiency has been detected in systemic autoimmune disorders, systemic lupus erythematosus, RA, and multiple sclerosis (MS) [21]. It is believed that IL-35 has an immunosuppressive activity that is mediated by both $\mathrm{T}$ and $\mathrm{B}$ - regulatory cells through IL-10 dependent mechanism [22]. IL-35 exerts an irreplaceable role in balancing between Th-17 and T-reg cells; IL-35 can induce differentiation of naive $\mathrm{T}$ cells to trigger T-reg cells (iTreg-35), which, in turn, secrete more IL-35 culminating in a positive feedback cycle. Otherwise, IL-35 restricts the generation and function of Th-17, which is crucial in the pathogenesis of several autoimmune diseases, psoriasis, MS, and IBD [21], [23].

It was found that IL-35 was significantly higher in RA patients with inactive arthritis compared to those with active disease, and a significant inverse correlation based on the CRP was observed between IL-35 and DAS -28 [24]. In the present study, IL-36 was significantly higher in JIA patients compared to healthy controls. Although little is known about the relevance of IL-36 to human diseases, it was recorded as a master linker between adaptive immunity and synovial autoimmune response in both RA and psoriatic arthritis. It is speculated that IL-36 $\alpha$ produced by plasma cells induces IL-36R in fibroblast-like synoviocytes and elicits the production of IL-6 and IL-8; this pathway represents a major trigger to give rise to an inflammatory 
environment since IL- 6 induces the synthesis of TNF- $\alpha$, while IL-8 is a potent neutrophil chemotactic factor that brings more neutrophils and other granulocytes to the joints, resulting in massive destruction [14], [25].

IL-36 not only induces cell destruction but also develops a bias toward pathogenic versus regulatory immune cells through their rule in T-cell differentiation and proliferation [26]. A previous in vivo study reported that IL-36 agonists promote murine dendritic cells maturation through the upregulation of CD-80, CD-86, and MHC-II molecules, and promote the production of pro-inflammatory mediators, IL-1 $\beta, \mathrm{IL}-6, \mathrm{IL}-12, \mathrm{IL}-23$, and TNF- $\alpha$ in an IL-36R-dependent mechanism. Further, this cytokine causes IL-36R-expressing CD-4 T-lymphocytes to produce interferon- $\gamma$ (INF- $\gamma$ ) and IL-17, and directly stimulate CD-4 T-lymphocytes to produce IL-17A [11]. Furthermore, the role of IL-36 has been delineated in developing autoimmune disorders via Th-1 and Th-17 dependent pathways. IL-17, TNF- $\alpha$, and IL-22 directly induce the production of IL-36, which, in turn, causes positive feedback and augments their own and other cytokines (IL-6 and IL-8) production. Further, IL-36 directly polarizes the differentiation of INF- $\gamma$, and Th-1 lymphocytes [11], [12].

The ratio of anti/pro-inflammatory cytokines is getting significant attention from rheumatologists and immunological researchers. In the present study, the IL-35/IL-36 ratio was significantly lower among JIA patients, and further, it was also significantly lower among those with severe JIA compared to mild and moderate disease. A dysregulation of pro- and anti-inflammatory cytokines has been reported to contribute to autoimmune diseases - INF- $\gamma /$ IL-10 ratio was significantly increased in non-segmental vitiligo compared to controls. Likewise, a deteriorated cytokine network contributes to the development of non-functional T-reg cells which are crucial in immune tolerance [27]. An imbalance between pro- and antiinflammatory cytokines was also recorded in conditions other than autoimmune diseases. A study conducted in 2015 showed that pro/anti-inflammatory cytokines ratios of different cytokines, INF- $\gamma /$ INFIL-4, INF- $\gamma /$ IL-10, and IL-6/IL-10, were significantly higher among people with recurrent implantation failure compared to controls [28]. An imbalance in the cytokine network has also been recorded in infectious diseases. A significant increase in the IL-8/IL-10, IL-8/TGF- $\beta$, IL-1 $\beta / \mathrm{IL}-10$, and IL-1 $\beta /$ TGF- $\beta 1$ ratios was recorded in the bronchoalveolar lavage fluid of patients with Pneumocystis jirovecii; a majority of these required mechanical ventilation and or did not survive [29].

Concerning the disturbance of ILs in respect to the three disease score groups, our results concur with a previous study that targeted IL-6 among RA patients of different disease scores. The author's recorded higher serum IL -6 levels in patients with severe disease scores, followed by those with mild scores, and finally those with moderate disease [30]. To the best of our knowledge, no study has explored the contribution and clinical relevance of circulating IL-35, IL-36, and their IL35/IL36 balance in the development of JIA.

The present study has several limitations. It included a small number of participants who were already receiving treatments and differed in their commitment to medication, all of which could affect the true cytokine levels. We propose that studying cytokine ratios in newly diagnosed patients will give more accurate and representative values.

\section{Conclusion}

Our results imply that $\mathrm{IL}-35, \mathrm{IL}-36$, and the IL-35/IL-36 ratio play a crucial role in JIA pathogenicity. The IL35/IL36 ratio, compared to individual cytokine values, is better to determine the inflammatory status in JIA. To the best of our knowledge, our research is the first to explore the role of IL-35 and IL-36 in JIA. Further researches are required to corroborate our results to determine whether these markers can be used as potential immunotherapies against JIA.

\section{References}

1. Bridges JM, Mellins ED, Cron RQ. Recent progress in the treatment of non-systemic juvenile idiopathic arthritis. Fac Rev. 2021;10:23. https://doi.org/10.12703/r/10-23

PMid:33718940

2. Bluestone JA, Bour-Jordan H. Current and future immunomodulation strategies to restore tolerance in autoimmune diseases. Cold Spring Harb Perspect Biol. 2021;4(11):a007542. https://doi.org/10.1101/cshperspect.a007542

PMid:23125012

3. Wareth G, Brandt C, Sprague LD, Neubauer H, Pletz MW. Spatiotemporal distribution of Acinetobacter baumannii in Germany-a comprehensive systematic review of studies on resistance development in humans (2000-2018). Microorganisms. 2020;8(3):375. https://doi.org/10.3390/microorganisms8030375 PMid:32155886

4. Poddighe D, Romano M, Gattinara M, Gerloni V. Biologics for the treatment of juvenile idiopathic arthritis. Curr Med Chem. 2018;25(42):5860-93. https://doi.org/10.2174/09298673256661 80522085716

PMid:29788871

5. Fischer R, Kontermann RE, Pfizenmaier K. Selective targeting of TNF receptors as a novel therapeutic approach. Front Cell Dev Biol. 2020;8:401. https://doi.org/10.3389/fcell.2020.00401 PMid:32528961

6. Lainka E, Baehr M, Raszka B, Haas JP, Hügle B, Fischer N, et al Experiences with IL-1 blockade in systemic juvenile idiopathic arthritis-data from the German AID-registry. Pediatr Rheumatol. 2021;19(1):38. https://doi.org/10.1186/s12969-021-00510-8 PMid:33752669 
7. Vijatov-Djuric G, Doronjski A, Mitic I, Brkic S, Barisic $\mathrm{N}$. Interleukin-17A levels increase in serum of children with juvenile idiopathic arthritis. Arch Rheumatol. 2017;32(3):234-43. https:// doi.org/10.5606/archrheumatol.2017.6067

PMid:30375522

8. Catalan-Dibene J, McIntyre LL, Zlotnik A. Interleukin 30 to interleukin 40. J Interferon Cytokine Res. 2018;38(10):423-39. https://doi.org/10.1089/jir.2018.0089

PMid:30328794

9. Choi J, Leung PSC, Bowlus C, Gershwin ME. IL-35 and autoimmunity: A comprehensive perspective. Clin Rev Allergy Immunol. 2015;49(3):327-32. https://doi.org/10.1007/ s12016-015-8468-9

PMid:25619872

10. Niedbala W, Wei XQ, Cai B, Hueber AJ, Leung BP, Mclnnes IB, et al. IL-35 is a novel cytokine with therapeutic effects against collagen-induced arthritis through the expansion of regulatory $\mathrm{T}$ cells and suppression of Th17 cells. Eur J Immunol. 2007;37(11):3021-9. https://doi.org/10.1002/eji.200737810 PMid: 17874423

11. Ding L, Wang $X$, Hong $X$, Lu L, Liu D. IL-36 cytokines in autoimmunity and inflammatory disease. Oncotarget. 2018;9(2):2895-901. https://doi.org/10.18632/oncotarget.22814 PMid:29416822

12. Han $Y$, Huard A, Mora J, da Silva P, Brüne B, Weigert A. IL-36 family cytokines in protective versus destructive inflammation. Cell Signal. 2020;75:109773. https://doi.org/10.1016/j. cellsig.2020.109773

PMid:32898612

13. Boutet MA, Nerviani A, Pitzalis C. IL-36, IL-37, and IL-38 cytokines in skin and joint inflammation: A comprehensive review of their therapeutic potential. Int J Mol Sci. 2019;20(6):1257. https://doi.org/10.3390/ijms20061257 PMid:30871134

14. Frey S. The novel cytokine interleukin- $36 \alpha$ is expressed in psoriatic and rheumatoid arthritis synovium. Ann Rheum Dis. 2013;72(9):1569-74. https://doi.org/10.1136/ annrheumdis-2012-202264

PMid:23268368

15. Mourão AF, Santos MJ, Melo-Gomes J, Martins FM, Costa JA, Ramos $F$, et al. Using the juvenile arthritis disease activity score based on erythrocyte sedimentation rate or C-reactive protein level: Results from the Portuguese register. Arthritis Care Res (Hoboken). 2014;66(4):585-91. https://doi.org/10.1002/acr.22215 PMid:25354266

16. Ćalasan MB, de vries LD, Vastert SJ, Heijstek MW, Wulffraat NM Interpretation of the Juvenile Arthritis Disease Activity Score: Responsiveness, clinically important differences and levels of disease activity in prospective cohorts of patients with juvenile idiopathic arthritis. Rheumatology (Oxford). 2014;53(2):307-12. https://doi.org/10.1093/rheumatology/ket310

PMid:24162034

17. Consolaro A, Ruperto N, Bazso A, Pistorio A, Magni-Manzoni S, Filocamo G, et al. Development and validation of a composite disease activity score for juvenile idiopathic arthritis. Arthritis Rheum. 2009;61(5):658-66. https://doi.org/10.1002/art.24516 PMid: 19405003

18. Fish J, Lipton J, Lanzkowsky $\mathrm{P}$, editors. Lanzkowsky's Manual of Pediatric Hematology and Oncology. Amsterdam, Netherlands: Elsevier Inc.; 2016. https://doi.org/10.1016/ b978-0-12-801368-7.00044-2
19. Li Y, Wang Y, Liu H, Ding K, Hao S, Shao Y, et al. Lower leve of IL-35 and its reduced inhibition in Th17 cells in patients with bone marrow mononuclear cells Coombs test-positive hemocytopenia. Mol Med Rep. 2018;17(2):2973-81. https://doi. org/10.3892/mmr.2017.8252 PMid:29257310

20. Zhang J, Zhang $\mathrm{Y}$, Wang $\mathrm{Q}$, Li C, Deng $\mathrm{H}$, Si C, et al. Interleukin-35 in immune-related diseases: Protection or destruction. Immunology. 2019;157(1):13-20. https://doi. org/10.1111/imm.13044

PMid:30681737

21. Guan SY, Leng RX, Khan MI, Qureshi H, Li XP, Ye DQ, et al. Interleukin-35: A potential therapeutic agent for autoimmune Diseases. Inflammation. 2017;40(1):303-10. https://doi. org/10.1007/s10753-016-0453-9 PMid:27696334

22. Bridgewood C, Alase A, Watad A, Wittmann M, Cuthbert R, McGonagle D. The IL-23p19/EBI3 heterodimeric cytokine termed IL-39 remains a theoretical cytokine in man. Inflamm Res. 2019;68(6):423-6. https://doi.org/10.1007/s00011-019-01235-x PMid:30989239

23. Zhao J, Lu Q, Liu Y, Shi Z, Hu L, Zeng Z, et al. Th17 cells in inflammatory bowel disease: Cytokines, plasticity, and therapies. J Immunol Res. 2021;2021:8816041. https://doi.org/10.1093/ rheumatology/keu528

PMid:33553436

24. Nakano S, Morimoto S, Suzuki S, Tsushima H, Yamanaka K, Sekigawa I, et al. Immunoregulatory role of IL-35 in T cells of patients with rheumatoid arthritis. Rheumatology (Oxford). 2015;54(8):1498-506.

PMid:25731770

25. Schmitt V, Hahn M, Kästele V, Wagner O, Wiendl M, Derer A et al. Interleukin-36 receptor mediates the crosstalk between plasma cells and synovial fibroblasts. Eur J Immunol. 2017;47(12):2101-12. https://doi.org/10.1002/eji.201646788 PMid:28857172

26. Yuan ZC, Xu WD, Liu XY, Liu XY, Huang AF, Su LC. Biology of il-36 signaling and its role in systemic inflammatory diseases. Front Immunol. 2019;10:2532. https://doi.org/10.3389/ fimmu.2019.02532 PMid:31736959

27. Lab Test: White Blood Cell Count, WBC. Available from: http:// www.genes-environment-inflammation.de/basic-page/grantsfunding-after-doctorate. [Last access on $2021 \mathrm{Feb} 14$ ].

28. Liang PY, Diao LH, Huang CY, Lian RC, Chen X, Li GG, et al. The pro-inflammatory and anti-inflammatory cytokine profile in peripheral blood of women with recurrent implantation failure. Reprod Biomed Online. 2015;31(6):823-6. https://doi. org/10.1016/j.rbmo.2015.08.009 PMid:26371706

29. Chou CW, Lin FC, Tsai HC, Chang SC. The importance of proinflammatory and anti-inflammatory cytokines in Pneumocystis jirovecii pneumonia. Med Mycol. 2013;51(7):704-12. https://doi. org/10.3109/13693786.2013.772689 PMid:23488973

30. Chung SJ, Kwon YJ, Park MC, Park YB, Lee SK. The correlation between increased serum concentrations of interleukin- 6 family cytokines and disease activity in rheumatoid arthritis patients. Yonsei Med J. 2011;52(1):113-20. https://doi.org/10.3349/ ymj.2011.52.1.113

PMid:21155043 